\title{
The Role of Umbilical Cord Thickness and Glycated Hemoglobin (HbA1c) Levels for Prediction of Fetal Macrosomia in Patients with Gestational Diabetes Mellitus Osama Elsaeed Ali Ismail, Ibrahim Ramadan Alsawy Rady, Mahmoud Fayez Mohamed Fathi* \\ Department of Obstetrics and Gynaecology, Faculty of Medicine, El-Azhar University \\ * Corresponding author: Mahmoud Fayez Mohamed Fathi, Mobile: (+20) 0109926 8044,
} E-mail: mahmoud.fayez66@gmail.com

\begin{abstract}
Background: Diabetes with pregnancy is a known clinical risk factor associated with fetal macrosomia. The rationale for performing an elective cesarean section includes a potential reduction in perinatal complications, especially those related to macrosomia.

Objective: This study aimed to assess the accuracy of HbA1c and umbilical cord thickness in prediction of fetal macrosomia in diabetic pregnant women.

Patients and Methods: The study included 100 diabetic pregnant, 27 - 28 weeks gestation, gathered from Inpatients and Obstetric Outpatient Clinic of Bab Alshariya University Hospital attending for routine antenatal care.

Results: At a criterion of $>211 \mathrm{~mm}^{2}$, the umbilical cord area measured at $27-28$ weeks of gestation was able to predict high birth weight (macrosomia), with a sensitivity of $90.5 \%$ and a specificity of $91.7 \%$. The area under the curve for the ROC was 0.9294 , with a $95 \%$ confidence interval of 0.8608 to 0.9702 , which was found to be statistically highly significant $(\mathrm{p}=0.0001)$. When compared the ROC curves of both the umbilical cord area and the glycated hemoglobin, it was found that umbilical cord area is more reliable in predicting fetal macrosomia at the right criterion, the difference between the predictive efficiency for both parameters was found to be statistically highly significant. Conclusion: Macrosomia is a cause of the worst of obstetric emergencies such as shoulder dystocia, birth asphyxia and postpartum haemorrhage. Shoulder dystocia cannot always be predicted accurately. However, predicting macrosomia can help to identify the population at risk of such complications.
\end{abstract}

Keywords: Umbilical cord thickness, Glycated hemoglobin (HbA1c), Macrosomia, Gestational diabetes mellitus.

\section{INTRODUCTION}

The umbilical cord is responsible for maternalfetal blood flow. Normally, it is composed of two arteries permeated with venous blood and a vein that transports arterial blood, cushioned by a special type of mucous connective tissue known as Wharton's jelly (WJ) and by remnants of the allantoids ${ }^{(1)}$.

There is a significant differences in mean gestational age, mode of delivery, birth weight and adverse perinatal outcome between fetuses with umbilical cord thickness below the $5^{\text {th }}$ percentile (lean umbilical cord) vs those with umbilical cord thickness above the $5^{\text {th }}$ percentile (non-lean cord) in the first and early second trimesters of gestation ${ }^{(2)}$.

Reported risk factors of macrosomia are body mass index (BMI) before pregnancy, gestational weight gain, gestational diabetes mellitus (GDM), mother's age and gender ${ }^{(3)}$.

GDM is associated with many adverse pregnancy outcomes such as macrosomia and CS delivery ${ }^{(4)}$. At the same time macrosomia is a well-known indicator of maternal diabetes in fetus which is strongly associated with prematurity, respiratory distress syndrome, birth trauma, fetal death and adverse maternal outcome ${ }^{(5)}$. Obesity in pregnancy is also recognized as a risk factor for many maternal and neonatal adverse outcomes including macrosomia, increased rate of cesarean section (CS), preeclampsia and gestational diabetes (GDM) ${ }^{(6)}$. In addition, the placenta, as the interface between mother and fetus, is central to prenatal growth control. The fetus is dependent upon the placenta for its supply of nutrients and oxygen from the mother. Previous research found that the placental weights in the macrosomic fetuses were significantly higher than those with normal weight and placental weight was positively correlated with birth weight ${ }^{(7)}$. Fetal macrosomia is associated with a higher frequency of operative deliveries, postpartum hemorrhages, birth injury during vaginal delivery and neonatal hypoglycemia. Known maternal risk factors are only identified in $40 \%$ of women who deliver macrosomic babies ${ }^{(8)}$. Macrosomia has been suggested as one of the possible risk factors for obesity in many studies ${ }^{(\boldsymbol{9})}$. Children with macrosomia tend to gain weight faster than those born at normal weight. Abnormal weight gain in the uterus and during infancy may have an adverse influence on health in childhood and adult life. Studies show that macrosomic infants have a higher risk of developing obesity and metabolic disorders ${ }^{(\mathbf{1 0})}$.

Diabetes represents a major public health concern and efforts to control hyperglycemia are an important element of the management of patients with type 2 diabetes (11). Hyperglycaemia is measured using hemoglobin A1c (HbA1c) test, which assesses the average level of blood glucose in the preceding 60-120 days. For diabetic patients an HbA1c target of $6.5 \%$ (48 $\mathrm{mmol} / \mathrm{mol})$ is recommended ${ }^{(11)}$.

Gestational diabetes mellitus (GDM) affects 2$6 \%$ of pregnant women and is associated with increased risk of important adverse perinatal 
outcomes, including macrosomia and birth injury ${ }^{(\mathbf{1 2})}$. Therefore, for the prevention of traumatic birth and adverse outcomes, many studies have been performed for predicting birth weight accurately. Through the accurate prediction of macrosomic fetuses that have risk of traumatic birth, the route of delivery may be changed. Ultrasound-based birth weight prediction is still insufficient. Investigators have attempted to improve ultrasound-based prediction of fetal macrosomia by various methods, such as the assessment of fat deposition at different locations. None of these methods have gained wide popularity because of the inability to accurately estimate fetal weight against conventional biometric formulas ${ }^{(\mathbf{1 3})}$.

Studies that have assessed umbilical cord components to predict fetal weight have shown that there is a correlation between umbilical cord diameter, area and fetal biometric parameters ${ }^{(14)}$. In addition, some observers have suggested that combination of these two methods should give more reliable results for estimating macrosomic fetuses ${ }^{(\mathbf{1 5})}$.

\section{AIM OF THE WORK}

This study aimed to assess the accuracy of HbAlc and umbilical cord thickness in prediction of fetal macrosomia in diabetic pregnant women.

\section{PATIENTS AND METHODS}

1. Setting: Bab Alshariya Hospital, Al-Azhar University

2. Design: Prospective - observational study to assess the accuracy.

3. Population: The study included 100 diabetic pregnant, 27 - 28 weeks gestation, gathered from Obstetric Inpatients and Outpatient Clinic of Bab Alshariya University Hospital attending for routine antenatal care.

\section{Sample Size Justification:}

The required sample size has been calculated using IBM $\odot$ Sample Power $\odot$ version 3 (IBM@ Corp., Armonk, NY).

\section{Diagnostic criteria of gestational diabetes mellitus:}

1-Fasting plasma glucose level $126 \mathrm{mg} / \mathrm{dl}(7.0 \mathrm{mmol} / \mathrm{l})$.

2-Random plasma glucose level $200 \mathrm{mg} / \mathrm{dl}$ (11.0 $\mathrm{mmol} / \mathrm{l})$.

3-Hemoglobin A1c 6.5\%

\section{Methodology:}

All included women after informed consent was subjected to:

a. Full history taking including personal, menstrual and past history.

b. Calculation of gestational age was based on the date of their last reliable menstrual period according to Naegele's rule and confirmed by ultrasound examination within the first trimester. c. Abdominal examination to assess the fundal height and estimated fetal weight.

d. Ultrasound examinations were performed with a Medison RS 3.7-mHz Convex transabdominal probe to measure umbilical cord thickness at 27 - 28 weeks gestation and repeated at $36-37$ weeks gestation.

e. Ultrasonographic examination included fetal anthropometric parameters, biparietal diameter (BPD), femur length (FL) and estimated fetal weight (EFW), which were calculated automatically according to Hadlock's formula.

f. HbA1c levels were measured at $27-28$ weeks and at full term. Measuring HbA1c can reveal as to how high the blood glucose has been on an average, over the past 8-12 weeks.

A normal non-diabetic HbA1c value is $3.5-5.5 \%$. In diabetics, range of $6.5 \%$ to $7 \%$ is good. In individuals with poorly controlled diabetes, the quantity of this glycated $\mathrm{Hb}$ is much higher than in healthy people ${ }^{(\mathbf{1 6})}$.

g. Macrosomia was considered when estimated fetal weight is over $4,000 \mathrm{gm}$.

h. Follow up of the patients at birth included mode of delivery, birth weight and fetal sex.

i. Population variability included age, BMI, parity, mode of delivery, estimated birth weight by ultrasound, birth weight, HbA1c and umbilical cord thickness.

The primary outcome measure is the accuracy of the umbilical cord thickness and HbAlc level for prediction of fetal macrosomia.

There is currently no adequate information regarding the expected area under the ROC curve (AUROC) for prediction of fetal macrosomia using the umbilical cord thickness and HbA1c. Therefore, the present study would target an AUROC that could be regarded as clinically relevant. It is generally held that for a predictive test to be valid, its AUROC should be at least $0.75^{(17)}$.

A previous study by Cromi et al. ${ }^{(18)}$ reported that approximately $18 \%$ of diabetic mothers would have macrosomic babies. Thus, it is estimated that recruiting 100 diabetic mothers would yield $18(18 \%)$ macrosomic babies (positive group) and $82(82 \%)$ non-macrosomic babies (negative group).

\section{Inclusion criteria:}

Pregnant women with:

1. 27 - 28 weeks gestation

2. Diabetes mellitus

3. Singleton gestation

4. Normal umbilical morphology (two arteries and one vein).

\section{Exclusion criteria:}

1. The presence of fetal congenital anomalies

2. Multifetal pregnancy

3. Pregestational diabetes mellitus 
4. Maternal chronic diseases (hypertension, renal disease, cardiac and pulmonary disease, etc. . .)

5. Patients with a diagnosis such as placenta previa, oligohydraminous, preeclampsia and intrauterine growth restriction

6. Smoking or alcohol cousumption during pregnancy

7. Preterm delivery

\section{Ethical issues:}

The protocol was presented for the Ethical Committee for approval.

\section{the study}

1. The hospital Ethics Committee approved

2. Consent process: the population sample under study was instructed about research protocol and signed informed consent was taken from each woman before inclusion in the study.

This sample size had a power of $91 \%$ (type II error, 0.09) to detect statistical significance for a difference of 0.25 between a null area under the ROC curve (AUROC) of 0.5 and an alternative AUROC of 0.75 associated with the umbilical cord thickness or HbA1c level. An AUROC of 0.75 has been chosen as it is considered to be the least AUROC for a diagnostic/predictive test to be clinical relevance.

This calculation used a two-sided $z$ test with a confidence level of 99\% (type I error, 0.01).

\section{Statistical methods}

Data were collected, tabulated, then analyzed using IBM@ SPSS $\odot$ Statistics version 22 (IBM c Corp., Armonk, NY). Normally distributed numerical data was presented as mean and SD and skewed data as median and interquartile range. Qualitative data was presented as number and percentage. Comparison of normally distributed numerical data was done using the unpaired student $t$-test. Skewed data was compared using Mann-Whitney U test. Categorical data were compared using Chi-squared test, or Fisher's exact test when appropriate. Receiver-operating characteristic (ROC) curve analysis was used to examine the value of the umbilical cord thickness or HbAlc level for prediction of fetal macrosomia. A two-sided p-value less than 0.05 was considered statistically significant.

\section{RESULTS}

The primary outcome was the feasibility of prediction of fetal macrosomia using umbilical cord area (thickness) and the glycated hemoglobin (HbA1c) level.

Both parameters were measured twice, first at 27 -28 weeks of gestation and second at $36-37$ weeks of gestation. In order to reach a statistically acceptable data, the total sample was divided into two subgroups:
- Macrosomic fetuses (positive group) group (1): 15 fetus.

- Non- macrosomic fetuses (negative group) group (2): 85 fetus.

A p-value at $<0.05$ was considered significant in all comparisons.

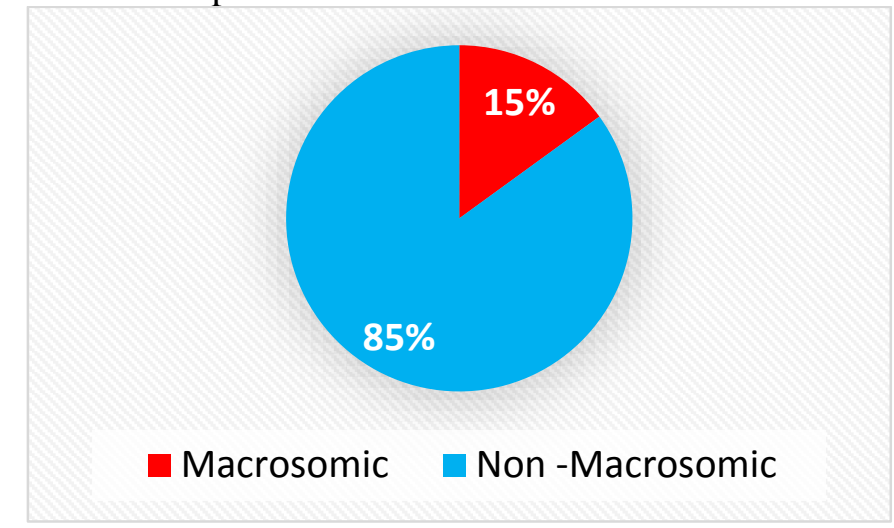

Figure (1): Study groups as regard macrosomia

Table (1): Comparison between both groups as regards the baseline parameters/ characteristics

\begin{tabular}{|c|c|c|c|c|}
\hline Parameter & $\begin{array}{c}\text { Group 1: } \\
\text { Macrosom } \\
\text { ic fetuses }\end{array}$ & $\begin{array}{c}\text { Group 2: } \\
\text { Non - } \\
\text { Macrosomi } \\
\end{array}$ & \begin{tabular}{|l}
$P$ P- \\
value
\end{tabular} & $\begin{array}{c}\text { Total } \\
\text { sample }\end{array}$ \\
\hline $\begin{array}{l}\text { Maternal } \\
\text { age }\end{array}$ & $26.6 \pm 4.4$ & $27.1 \pm 3.8$ & \multirow{4}{*}{0.5} & $27.2 \pm 4.1$ \\
\hline $20-25$ & $5(33 \%)$ & $29(34 \%)$ & & $36(36 \%)$ \\
\hline $26-30$ & $7(47 \%)$ & $34(40 \%)$ & & $39(39 \%)$ \\
\hline $31-35$ & $3(20 \%)$ & $22(26 \%)$ & & $25(25 \%)$ \\
\hline Gravidity & $3.6 \pm 1.3$ & $2.5 \pm 1.2$ & $0.01 *$ & $3.0 \pm 1.1$ \\
\hline Parity & $3.0 \pm 1.4$ & $2.7 \pm 1.2$ & 0.2 & $2.3 \pm 1.2$ \\
\hline \multicolumn{5}{|l|}{ Fetal sex } \\
\hline Male & $6(40 \%)$ & $38(45 \%)$ & 0.7 & $44(44 \%)$ \\
\hline Female & $9(60 \%)$ & $47(55 \%)$ & .62 & $56(56 \%)$ \\
\hline \multicolumn{3}{|c|}{ Body mass index (BMI) } & \multirow{4}{*}{$\begin{array}{l}<0.00 \\
1 * *\end{array}$} & \\
\hline $19-24.9$ & $2(13 \%)$ & $45(53 \%)$ & & $47(47 \%)$ \\
\hline $25-29.9$ & $8(54 \%)$ & $34(40 \%)$ & & $42(42 \%)$ \\
\hline$\geq 30$ & $5(33 \%)$ & $6(7 \%)$ & & $11(11 \%)$ \\
\hline
\end{tabular}

As shown in table (1), the maternal age did not differ significantly between both groups, most of them were between 20 and 30 years of age $(36 \%, 39 \%$, respectively), however, almost one-third of group (2) women were above 30 years of age $(31-35$ years; $25 \%$, respectively), however, still no significant difference was noted when compared the proportions in the two groups. Group (1) had a mean maternal age of $26.6 \pm 4.4$ years, group (2) had a mean maternal age of $27.1 \pm 3.8$ years and the total sample had a mean maternal age of $27.2 \pm 4.1$ years old. 
As regards the gravidity, both groups differed significantly where group (1) subjects/women had a mean of $3.6 \pm 1.3$ against $2.5 \pm 1.2$ for group (2) subjects/women, however, both group did not differ in parity.

Macrosomic group had a higher proportion of female sex fetuses (60\%) against $40 \%$ male fetuses and nonmacrosomic group showed $44 \%$ males and 56\% females. however, when compared males and females proportion against each group did not differ significantly.

Among the 15 patients who delivered macrosomic fetus, 5 women (33\%) were obese, 8 (54\%) were overweight and $2(13 \%)$ were normal.

Table (2): Comparison between both groups as regards the delivery data

\begin{tabular}{|c|c|c|c|c|}
\hline Parameter & $\begin{array}{c}\text { Group 1: } \\
\text { Macrosomic } \\
\text { fetuses } \\
(n=15)\end{array}$ & $\begin{array}{c}\text { Group 2: } \\
\text { Non- } \\
\text { Macrosomic } \\
\text { fetuses } \\
(\mathbf{n}=\mathbf{8 5})\end{array}$ & $\begin{array}{c}\text { P- } \\
\text { value }\end{array}$ & $\begin{array}{c}\text { Total } \\
\text { sample } \\
(\mathbf{n = 1 0 0})\end{array}$ \\
\hline $\begin{array}{l}\text { GA at } \\
\text { delivery } \\
\text { (Wee }\end{array}$ & $36.1 \pm 2.2$ & $36.9 \pm 1.7$ & \multirow{3}{*}{$\begin{array}{l}0 \\
\dot{3}\end{array}$} & $37.1 \pm 1.2$ \\
\hline $34-40$ & $13(95 \%)$ & $78(92 \%)$ & & $91(91 \%)$ \\
\hline$>40$ & $2(5 \%)$ & $7(8 \%)$ & & $9(9 \%)$ \\
\hline $\begin{array}{l}\text { Birth } \\
\text { weight } \\
\text { (gm) }\end{array}$ & $\begin{array}{c}3924.9 \pm \\
418.3\end{array}$ & $\begin{array}{c}3332.3 \pm \\
296.1\end{array}$ & \begin{tabular}{c|}
$<$ \\
0.00 \\
$01 * *$
\end{tabular} & $\begin{array}{c}3418.3 \pm \\
378.2\end{array}$ \\
\hline \multicolumn{5}{|c|}{ Mode of delivery } \\
\hline $\begin{array}{l}\text { Cesarean } \\
\text { Section }\end{array}$ & $11(74 \%)$ & $36(42 \%)$ & $\begin{array}{c}\mathbf{0 . 0 2} \\
*\end{array}$ & $47(47 \%)$ \\
\hline $\begin{array}{l}\text { Vaginal } \\
\text { Delivery }\end{array}$ & $4(26 \%)$ & $49(58 \%)$ & $\begin{array}{c}\mathbf{0 . 0 2} \\
*\end{array}$ & $53(53 \%)$ \\
\hline \multicolumn{5}{|c|}{$\begin{array}{l}\text { (*) Significant } \\
(* *) \text { Highly Significant }\end{array}$} \\
\hline
\end{tabular}

As regards the gestational age at delivery, the total sample had a mean gestational age $37.1 \pm 1.2$ weeks. In comparing both groups regarding the number of deliveries at full term and post-term, no statistically significant difference was found. However, both groups differed in the birth weight of the delivered fetuses, group 1 had a mean birth weight of $3924.9 \pm 418.3 \mathrm{gm}$ (for 15 fetuses) versus $3332.3 \pm 296.1 \mathrm{gm}$ (for 85 fetuses), which was highly significant $(\mathrm{p}<0.0001)$.

Moreover, due to large baby size, both subgroups differed significantly as regards the mode of delivery, where $74 \%$ of group (1) women delivered by cesarean section against $42 \%$ of group (2) women (Table 2).
Table (3): Comparison between both groups as regards the glycated hemoglobin levels (HbA1c \%), measured at $27-28$ weeks and $36-37$ weeks of gestation

\begin{tabular}{|c|c|c|c|c|}
\hline $\begin{array}{l}\text { HbA1c (\%) } \\
\text { of groups 1 } \\
\mathbf{8} 2\end{array}$ & $\begin{array}{c}\text { Group 1 } \\
\text { Macrosomic } \\
\text { fetuses (15) } \\
\text { (weeks) }\end{array}$ & $\begin{array}{c}\text { Group 2 } \\
\text { Non- } \\
\text { macrosomic } \\
\text { fetuses (85) }\end{array}$ & $\begin{array}{c}\text { P- } \\
\text { value }\end{array}$ & $\begin{array}{c}\text { Total } \\
\text { sample } \\
\text { (n= 100) }\end{array}$ \\
\hline $27-28$ & $6.1 \pm 0.2$ & $6.3 \pm 0.3$ & 0.2 & $6.2 \pm .4$ \\
\hline $36-37$ & $6.4 \pm 0.3$ & $5.8 \pm 0.4$ & $<$ & $6.1 \pm 0.3$ \\
& & $\mathbf{0 . 0 0 0 1} * *$ & \\
\hline
\end{tabular}

As regards the glycated hemoglobin, both groups did not differ significantly when compared at $27-$ 28 weeks of gestation, where subgroup 1 had a mean $\mathrm{HbA} 1 \mathrm{c}$ of $6.1 \pm 0.2 \%$ vs $6.3 \pm 0.3 \%$ for subgroup 2, while the total sample had a mean of $6.2 \pm$ $0.4 \%$.

At 36 - 37 weeks of gestation, we found that group 1 had a higher HbA1c levels than group 2 (6.4 \pm $0.3 \%$ vs $5.8 \pm 0.4 \%$, respectively), which was highly statistically significant $(\mathrm{p}<0.0001)$, while the total sample had a mean of $6.1 \pm 0.3 \%$.

Table (4): Comparison between both groups as regards the umbilical cord area (UCA $\mathrm{mm}^{2}$ ), measured at 27 28 weeks and $36-37$ weeks of gestation

\begin{tabular}{|c|c|c|c|c|}
\hline \begin{tabular}{l}
\multicolumn{2}{c}{ UCA } \\
$\left(\mathrm{mm}^{2}\right)$ of groups \\
$1 \&$ \\
2 \\
2
\end{tabular} & $\begin{array}{c}\text { Group 1 } \\
\text { Macroso } \\
\text { mic } \\
\text { fetuses } \\
(\mathrm{n}=15) \\
\text { UCA }\end{array}$ & $\begin{array}{c}\text { Group } 2 \\
\text { Non- } \\
\text { macrosomi } \\
\text { c fetuses } \\
(\mathrm{n}=85) \\
\text { UCA }\end{array}$ & P-value & $\begin{array}{c}\text { Total } \\
\text { sample } \\
(\mathrm{n}=\mathbf{1 0 0})\end{array}$ \\
\hline $\begin{array}{l}27-28 \text { Weeks of } \\
\text { Gestation }\end{array}$ & $\begin{array}{c}213.1 \pm \\
2.8\end{array}$ & $\begin{array}{c}204.2 \pm \\
2.1 \\
\end{array}$ & $\begin{array}{c}<0.0001 * \\
*\end{array}$ & $\begin{array}{c}209.1 \pm \\
3.2\end{array}$ \\
\hline $\begin{array}{l}36-37 \text { Weeks of } \\
\text { Gestation }\end{array}$ & $\begin{array}{c}232.1 \pm \\
3.1\end{array}$ & $\begin{array}{c}215.4 \pm \\
4.3\end{array}$ & $\begin{array}{c}<0.0001 * \\
*\end{array}$ & $\begin{array}{c}219.1 \pm \\
6.8\end{array}$ \\
\hline $\begin{array}{l}(* *) \text { Highly } \\
\text { Significant }\end{array}$ & & & & \\
\hline
\end{tabular}

As shown in table (4), both subgroups differed highly significantly as regards the umbilical cord area, group $1 \mathrm{had}$ a mean UCA of $213.1 \pm 2.8 \mathrm{~mm}^{2}$ at $27-28$ weeks of gestation against $204.2 \pm 2.1 \mathrm{~mm}^{2}$ for group 2. While the total sample had a mean UCA of $209.1 \pm$ $3.2 \mathrm{~mm}^{2}$.

At 36 - 37 weeks of gestation, the total sample had a mean UCA of $219.1 \pm 6.8 \mathrm{~mm}^{2}$. Group (1) had a mean 
of $232.1 \pm 3.1 \mathrm{~mm}^{2}$ against $215.4 \pm 4.3 \mathrm{~mm}^{2}$ for group (2).

Table (5): Relationship between birth weight (gm) and the umbilical cord area (UCA mm2) measured at $27-28$ weeks and $36-37$ weeks of gestation in group 1 (Macrosomic fetuses; $\mathrm{n}=15$ )

\begin{tabular}{|c|c|c|c|}
\hline Parameter & $\begin{array}{c}\text { Correlation } \\
\text { Coefficient } \\
\text { value }(\boldsymbol{r})\end{array}$ & $\begin{array}{c}\mathbf{9 5 \%} \text { CI } \\
\text { for r }\end{array}$ & P-value \\
\hline $\begin{array}{c}27 \text { - 28 Weeks } \\
\text { of Gestation }\end{array}$ & 0.7340 & 0.4452 to \\
0.8903 & $\mathbf{0 . 0 0 0 2} * * *$ \\
\hline $\begin{array}{c}36-37 \text { Weeks } \\
\text { of Gestation }\end{array}$ & 0.7483 & $\begin{array}{c}0.4611 \text { to } \\
0.8934\end{array}$ & $\mathbf{0 . 0 0 0 1 * * *}$ \\
\hline CI: Confidence Interval $(* *)$ Highly Significant \\
\hline
\end{tabular}

When correlated the birth weight to the umbilical cord area in group 1 (Macrosomic fetuses), it was found that there was a strong, dependent and positive (direct) correlation between both parameters, either measurement at $27-28$ weeks or measurement at $36-37$ weeks of gestation $(r=0.7340 \& 0.7483$, respectively). Moreover, these correlations were found to be statistically highly significant $(p=0.0002 \& 0.0001$, respectively).

Table (6): Relationship between birth weight (gm) and the glycated hemoglobin (HbA1c \%) measured at $27-28$ weeks and $36-37$ weeks of gestation in group 1 (Macrosomic fetuses: $\mathrm{n}=15$ )

\begin{tabular}{|c|c|c|c|}
\hline Parameter & $\begin{array}{c}\text { Correlation } \\
\text { Coefficient value } \\
(\boldsymbol{r})\end{array}$ & $\begin{array}{c}\mathbf{9 5 \%} \mathbf{C I} \\
\text { for r }\end{array}$ & $\begin{array}{c}\text { P- } \\
\text { value }\end{array}$ \\
\hline $27-28$ & -0.06735 & -0.4912 to & 0.7 \\
$\begin{array}{c}\text { Weeks of } \\
\text { Gestation }\end{array}$ & & 0.3844 & \\
\hline $36-37$ & 0.3886 & -0.06157 & 0.08 \\
Weeks of & & to 0.7102 & \\
\hline \multicolumn{4}{|l|}{ CI: Confidence Interval } \\
\hline
\end{tabular}

Table (6) showed that the glycated hemoglobin neither had a strong nor significant correlation with the birth weight, neither measurement at $27-28$ weeks nor measurement at $36-37$ weeks of gestation.

Table (7): Receiver-Operator Characteristic (ROC) Curve analysis of the predictive value of the Umbilical Cord Area (UCA; mm2) at $27-28$ weeks of gestation and the birth weight $(\mathrm{gm})$

\begin{tabular}{|l|c|}
\hline Parameter & Value \\
\hline Positive Sample Size & 15 \\
\hline Negative Sample Size & 85 \\
\hline Area Under the Curve (AUC) & 0.9294 \\
\hline Standard Error & 0.03712 \\
\hline z Statistic & 11.433 \\
\hline 95\% Confidence Interval & 0.8608 to 0.9702 \\
\hline
\end{tabular}

\begin{tabular}{|l|c|}
\hline $\mathrm{P}($ Area $=0.5)$ & $\mathbf{0 . 0 0 0 1} * *$ \\
\hline$(* *)$ Highly Significant & \\
\hline
\end{tabular}

At a criterion of $>211 \mathrm{~mm}^{2}$, the umbilical cord area measured at $27-28$ weeks of gestation was able to predict high birth weight (macrosomia), with a sensitivity of $90.5 \%$ and a specificity of $91.7 \%$. As shown in table (7), the area under the curve for the ROC was 0.9334 , with a $95 \%$ confidence interval of 0.8631 to 0.9715 , which was found to be statistically highly significant $(\mathrm{p}=0.0001)$.

Table (8): Receiver - Operator Characteristic Curve (ROC) comparison between umbilical cord area (UCA; mm2) and the glycated hemoglobin (HbA1c; $\%$ ) for the prediction of fetal macrosomia

\begin{tabular}{|l|l|l|l|}
\hline Parameter & AUC & SE & 95\% CI \\
\hline HbA1c (\%) & 0.553 & 0.0676 & 0.469 to 0.648 \\
\hline UCA $\left(\mathrm{mm}^{2}\right)$ & 0.914 & 0.0365 & 0.861 to 0.959 \\
\hline AUC: Area Under the Curve \\
SE: Standard Error \\
CI: Confidence Interval \\
\hline
\end{tabular}

\begin{tabular}{|c|c|}
\hline \multicolumn{2}{|c|}{$\begin{array}{l}\text { Pair wise comparison of ROC curves (HbA1c vs. } \\
\text { UCA) }\end{array}$} \\
\hline Difference between areas & 0.346 \\
\hline Standard Error & 0.0701 \\
\hline $95 \%$ Confidence Interval & 0.208 to 0.489 \\
\hline Z statistic & 4.981 \\
\hline P-value & $0.0001 * *$ \\
\hline
\end{tabular}

As shown in table (8), when compared the ROC curves of both the umbilical cord area and the glycated hemoglobin, it was found that umbilical cord area was more reliable in predicting fetal macrosomia at the right criterion. The difference between the predictive efficiency for both parameters was found to be statistically highly significant.

\section{DISCUSSION}

The relationship between umbilical cord components, $\mathrm{HbAlc}$, and fetal macrosomia was evaluated at 27-28 gestational weeks. Macrosomic fetuses were compared to non-macrosomic fetuses. Umbilical cord area and Wharton's jelly values were statistically different for each group as macrosomic fetuses had a mean umbilical cord area of $213.1 \pm 2.8$ $\mathrm{mm}^{2}$ against $204.2 \pm 2.1 \mathrm{~mm}^{2}$ for non-macrosomic group. Cord diameter, umbilical artery and vein area values were not statistically different between groups at this gestational time point.

However, at 36-37 gestational weeks at the second examination, an assessment of the relationship between umbilical cord components and 
fetal macrosomia revealed that all umbilical cord parameters were statistically different for both groups when macrosomic fetuses compared to nonmacrosomic ones, as mean umbilical cord area for macrosomic group was $232.1 \pm 3.1 \mathrm{~mm}^{2}$ against $215.4 \pm 4.3 \mathrm{~mm}^{2}$ for non macrosomic group.

As regards the glycated hemoglobin, both groups did not differ significantly when compared the levels measured at 27-28 weeks of gestation. While, at 36-37 weeks of gestation, the macrosomic group had a higher HbA1c than group $2(6.4 \pm 0.3 \%$ versus $5.8 \pm 0.4 \%$ respectively), which was highly statistically significant. The previously mentioned results are in agreement with those of a published research, at which the authors found a positive correlation between the umbilical cord area and the birth weight (gm), especially when estimated at the beginning of the third trimester ${ }^{(15)}$. Birol et al. ${ }^{(15)}$ assessed umbilical cord components to predict fetal weight and showed that there was a correlation between umbilical cord diameter area and fetal biometric parameters. In addition, some suggested that combination of these two methods should give more reliable results for estimating macrosomic fetuses. The study found that the relationship between umbilical cord thickness and fetal macrosomia was specific for diabetic patients, as it was non-significant in the non-macrosomic fetuses' subgroup. These data are in disagreement with the reported data of Birol et al. ${ }^{(15)}$ where the correlation was also significant for the control group. However, this might be due to the fact that their study design was based on cases controls design, while ours was including all as patients, no controls.

In addition, some other studies have shown that the presence of a lean umbilical cord in the second trimester may cause low birth weight and results in more fetal distress in labor. Besides, they showed that umbilical cord diameter and area measurements are associated with increased fetal macrosomia ${ }^{(\mathbf{1 8})}$.

Hadlock formula based on fetal biometric measurements that are still in use and maintains its importance. For all that, ultrasound-based fetal weight prediction is still insufficient. The positive predictive value of estimated fetal weight (EFW) varies between 60 and $79 \%{ }^{(19)}$. Cromi et al. (18) suggested that when EFW and umbilical cord area are combined together, the positive predictive value for macrosomic fetuses is significantly improved. In addition, the assessment of the umbilical cord area and its components does not seem to be influenced by gestational age or amniotic fluid volume. They reported through a period of approximately 2 weeks from ultrasound examination till delivery a results that were similar to our study.

Using multiple logistic regression models in 181,479 deliveries for comparing birth outcome of women with and without familial history of DM, it has been shown that women with a familial history of DM $(n=13,813)$ had a higher rate of fetal macrosomia compared to controls $(\mathrm{p}<0.001)$ and a 1.3 - fold increase in the risk for cesarean section ( $\mathrm{p}$ $<0.001)^{(20)}$.

Naylor et al. ${ }^{(21)}$ reported that the incidence of macrosomia was $16-29 \%$ in patients who had gestational diabetes mellitus (GDM) and10\% in the normal population. The relative risk of macrosomia varies between 1.5 and 3 times higher in the diabetic population. In our study, 6 of $41(14.6 \%)$ patients with GDM or pre-gestational diabetes mellitus delivered macrosomic fetuses, while 5 of 50 (10\%) fetuses delivered by non-diabetic patients were macrosomic. The relative risk of macrosomia for the diabetic group was found to be 1.5 times higher.

Additionally, Naylor et al. ${ }^{(21)}$ reported that the cesarean section rate for mothers with GDM was $30 \%$, while it was $20 \%$ in the control group. Interestingly, in Naylor's study, the birth weight of infants whose mothers were diagnosed with GDM was normal. This shows that cesarean section was preferred to vaginal delivery in diabetic patients, even if the birth weight was normal. It was the same for our study, the cesarean section rate of the diabetic group (73.2\%) was higher than in the control group $(32 \%)$. We thought that primary reason of this extremely high number of cesarean section was medicolegal aspects related to diabetic fetus dystocia and secondary, a number of previous cesarean sections was higher in the study group than in the control group.

In addition, Kamana et al. ${ }^{(22)}$ showed that delivery by cesarean section was higher in mother with macrosomic fetuses than non-macrosomic fetuses, which in turn is in agreement with our currently reported data. In the literature, postprandial blood glucose levels have been shown to be correlated with macrosomia ${ }^{(22)}$.

\section{CONCLUSION}

Macrosomia is a cause of worst obstetric emergencies such as shoulder dystocia, birth asphyxia and postpartum haemorrhage. Shoulder dystocia cannot always be predicted accurately. However, predicting macrosomia can help to identify the population at risk of such complications. Several studies of sonographic measurement for predicting of fetal macrosomia were established. Umbilical cord thickness and fetal fat layer are good predictors of fetal macrosomia.

In the assessment of risk of macrosomia in addition to the ultrasonographic measurements the clinical risk factors must be considered. Further studies are needed to evaluate the clinical value of 
incorporating these soft tissue measurements in formulas for estimation of fetal weight.

\section{REFERENCES}

1. Wang HS, Hung SC, Peng ST et al. (2004): Mesenchymal stem cells in the Wharton's jelly of the human umbilical cord. Stem Cells, 22: 1330-1337.

2. Goynumer G, Ozdemir A, Wetherilt L et al. (2008): Umbilical cord thickness in the first and early second trimesters and perinatal outcome. J Perinat Med., 36: 5236.

3. Yu DM, Zhai FY, Zhao LY et al. (2008): Incidence of fetal macrosomia and influencing factors in China in 2006. Chin J Prevent Med., 16: 11-13.

4. Barakat MN, Youssef RM, Al-Lawati JA (2010): Pregnancy outcomes of diabetic women: charting Oman's progress towards the goals of the Saint Vincent Declaration. Ann Saudi Med., 30: 265-270.

5. Yessoufou A, Moutairou K (2011): Maternal diabetes in pregnancy: early and long-term outcomes on the offspring and the concept of "metabolic memory". Exp Diabetes Res., 21: 85-98.

6. Athukorala C, Rumbold AR, Willson KJ et al. (2010): The risk of adverse pregnancy outcomes in women who are overweight or obese. BMC Pregnancy Childbirth, 10: 56-59.

7. Hua J, Pengcheng X, Guanghua L et al. (2009): Levels of insulin-like growth factors and their receptors in placenta in relation to macrosomia. Asia Pacif J Clin Nutrition, 18: 171-8.

8. Auger N, Park AL, Zoungrana H et al. (2013): Widening inequality in extreme macrosomia between Indigenous and non-Indigenous populations of Québec, Canada. Aust N Z J Public Health, 37 (1): 58-62.

9. Satpathy HK, Fleming A, Frey D et al. (2008): Maternal obesity and pregnancy. Postgrad Med., 120: 019.

10. Dyer JS, Rosenfeld CR, Rice J et al. (2007): Insulin resistance in Hispanic large-for-gestational-age neonates at birth. J Clin Endocrinol Metab., 92 (10): 3836-3843.

11. International Diabetes Federation (2013): Global Guidelines for Type 2 Diabetes: Brussels, Belgium: IDF. International Association of Diabetes and Pregnancy Study Groups Consensus Panel (IADPSGCP). Diabetes Care, 33: 676-682.
12. Hong J, Chadha Y, Donovan T et al. (2009): Fetal macrosomia and pregnancy outcomes. Aust N Z J Obstet Gynaecol., 49 (5): 504-509.

13. Bethune $M$, Bell $R$ (2003): Evaluation of the measurement of the fetal fat layer, interventricular septum and abdominal circumference percentile in the prediction of macrosomia in pregnancies affected by gestational diabetes. Ultrasound Obstet Gynecol., 22: 586-590.

14. Raio L, Ghezzi F, Di Naro E et al. (2003): Perinatal outcome of fetuses with a birth weight greater than 4500 g: an analysis of 3356 cases. Eur J Obstet Gynecol Reprod Biol., 109: 160-165.

15. Birol B, Yeniel AO, Ergenoglu AM et al. (2012): The role of umbilical cord thickness and $\mathrm{HbA} 1 \mathrm{c}$ levels for the prediction of fetal macrosomia in patients with gestational diabetes mellitus. Arch Gynecol Obstet., 285 (3): 635-9.

16. Rohlfing CL, Wiedmeyer HM, Little RR et al. (2002): Defining the relationship between plasma glucose and HbA1c: analysis of glucose profiles and HbA1c in the Diabetes Control and Complications Trial. Diabetes Care, 25 (2): 275-8.

17. Fan J, Upadhe S, Worster A (2009): Understanding receiver operating characteristic (ROC) curves. CJEM., 8: $19-20$.

18. Cromi A, Ghezzi F, Di Naro E et al. (2007): Large cross- sectional area of the umbilical cord as a predictor of fetal macrosomia. Ultrasound Obstet Gynecol., 30: 861-866.

19. Boney CM, Verma A, Tucker $R$ et al. (2005): Metabolic syndrome in childhood: association with birth weight, maternal obesity, and gestational diabetes mellitus. Pediatrics, 115 (3): 290-296.

20. Sprehe MR, Barahmani N, Cao Y et al. (2010): Comparison of birth weight corrected for gestational age and birth weight alone in prediction of development of childhood leukemia and central nervous system tumors. Pediatr Blood Cancer, 54: 242-249.

21. Naylor CD, Sermer M, Chen E et al. (1996): Cesarean delivery in relation to birth weight and gestational glucose tolerance: pathophysiology or practice style? Toronto Trihospital Gestational Diabetes Investigators. JAMA., 275: 1165-70.

22. Kamana KC, Shakya S, Zhang H (2015): Gestational Diabetes Mellitus and Macrosomia: A Literature Review. Ann Nutr Metab., 66 (2): 14-20. 